\title{
A CLINICAL METHOD FOR THE APPROXIMATE DETERMINA- TION OF SERUM CREATININE CONCENTRATION
}

\author{
By T. ADDIS, EVALYN BARRETT, AND JEAN T. MENZIES \\ (From the Department of Medicine, Stanford University School of Medicine, \\ San Francisco, Califormia)
}

(Received for publication January 28, 1947)

In our two preceding papers $(1,2)$ we have given measures of the variability of blood urea and serum creatinine concentrations in normal individuals who were taking known amounts of food protein. These standards have been found useful in forming an opinion as to the renal status of ambulatory patients with proteinuria. As time goes by and successive measurements are made we are able to judge the direction of change in the functional capacity of their kidneys. Such data are of primary clinical value because they are elements in the more complex judgments on which therapeutic decisions depend. But our own experience has forced us to conclude that these methods require supplementation by some procedure more in consonance with the immediate and practical requirements of day to day clinical work. Every day, in every clinic for renal disease, there are apt to be several new patients in whom an answer to the question as to the extent of their renal lesion is needed. This is not usually obtainable from their histories and physical examinations or from the state of their urines. At best these methods may suggest the existence of suburemic or uremic states, but at times they fail us altogether. It is the determination of the concentration of creatinine in the serum that transforms these indications into knowledge on which treatment can be based. Now, in theory, there is no reason why a precise measurement of creatinine cannot be obtained within half an hour or so of drawing the patient's blood. But this determination involves a complete separation from the patient and an absorption in technique that may be inadvisable or impossible. It is then that we need a quick approximate measure of the serum creatinine level to be used for the purpose of general orientation and immediate preliminary treatment.

We happened one day to observe that when the alkaline sodium picrate used for the determination of creatinine was added to whole serum the mixture remained quite clear. As the tube was watched, the orange color of creatinine picrate was seen to appear but as time went on the color deepened so that a few hours later it had become a deep orange, far deeper than the color derivable from the creatinine in the serum we were using. It seemed that there must be some chromogen other than creatinine in whole serum. The two colors can, however, be distinguished. The creatinine color develops quickly, even faster in serum than in a protein-free filtrate from the same serum, whereas the non-creatinine color develops very slowly. In Figure 1 it is shown that within 6 minutes after the addition of alkaline picrate to serum the rate of color formation has already become asymptotic. By making the determinations at 6 minutes we were thus able to measure the quantities of creatinine we added to serum.

In the clinical method we describe, the creatinine color in the serum is read against potassium dichromate standards. The comparison is facilitated by diluting the standard alkaline picrate solution with an equal volume of water. This solution is conveniently prepared by adding $1 \mathrm{ml}$. of 10 per cent sodium hydrate to $5 \mathrm{ml}$. of 1.175 per cent picric acid, and diluting with water to $12 \mathrm{ml}$. If care is taken to avoid parallax errors this can be done in a $15-\mathrm{ml}$. graduated centrifuge tube, adding the required volumes to the mark by means of capillary pipettes. One $\mathrm{ml}$. of the thoroughly mixed alkaline picrate is then added to $0.5 \mathrm{ml}$. of serum and an interval timer is set to ring at 6 minutes. The mixture of serum and picrate is then poured into a 4 - by $1 / 2$-inch test tube similar to the sealed tubes in which the potassium dichromate standards are kept. Tubes that have the same or almost the same diameter, by caliper measurement, and that are made of the same colored glaiss are selected. In comparing the colors we use a 3-slot comparator with a ground glass background illuminated by a daylight bulb. After 3 or 4 minutes the comparison with the standards may be started, but the final decision must be made 




Fre. 1

when the bell rings 6 minutes after the picrate is added to the serum.

It is curious and fortunate that the colors of certain concentrations of potassium dichromate and of creatinine picrate in sodium picrate should be indistinguishable by eye and should give almost an identical light absorption when a 520 filter is used. It was potassium dichromate that Folin used as a standard in his first creatinine determinations (3). Not only do potassium dichromate solutions give a perfect match but, once evaporation is prevented, they remain unchanged for years. In Table I we list the quantities of potassium dichromate that, when dissolved in water and brought to a volume of $100 \mathrm{ml}$., give colors corresponding with the colors that develop in 6 minutes in sera containing the designated creatinine concentrations (mgm. creatinine per, $100 \mathrm{ml}$. of serum).

Provided that the few measurements are made with care and granted that the user has the capacity to distinguish shades of yellow and orange, it has been found by many that this method is of value in the immediate management of new patients. It cannot give, of course, a continuous series of creatinine concentrations for classification, but it does afford grounds for the division of our pa- 
TABLE I

Potassium dichromate concentrations (mgm. potassium dichromate dissolved in water and brought to 100-ml. volume)

These concentrations have colors that are equivalent to the colors obtained by the direct and filtrate clinical methods from sera containing the given concentrations of creatinine (mgm. creatinine per $100 \mathrm{ml}$. of serum).

\begin{tabular}{|c|c|c|c|}
\hline \multicolumn{2}{|c|}{ Direct method } & \multicolumn{2}{|c|}{ Filtrate method } \\
\hline $\begin{array}{l}\text { Potassium } \\
\text { dichromate }\end{array}$ & $\begin{array}{l}\text { Serum } \\
\text { creatinine } \\
\end{array}$ & $\begin{array}{l}\text { Potassium } \\
\text { dichromate }\end{array}$ & $\underset{\text { creatinine }}{\text { Serum }}$ \\
\hline \multicolumn{2}{|c|}{ mgm. per $100 \mathrm{ml}$. } & \multicolumn{2}{|c|}{ mgm. per $100 \mathrm{ml}$. } \\
\hline $\begin{array}{r}200 \\
250 \\
300 \\
350 \\
400 \\
450 \\
500 \\
600 \\
700 \\
800 \\
900 \\
1000 \\
1500 \\
2000 \\
3000 \\
4000 \\
5000 \\
6000\end{array}$ & $\begin{array}{r}0.47 \\
0.64 \\
0.80 \\
0.98 \\
1.15 \\
1.31 \\
1.48 \\
1.80 \\
2.10 \\
2.40 \\
2.69 \\
2.96 \\
4.15 \\
5.24 \\
7.10 \\
8.62 \\
9.88 \\
10.97\end{array}$ & $\begin{array}{r}50 \\
100 \\
200 \\
300 \\
400 \\
500 \\
600 \\
700 \\
800 \\
900 \\
1000 \\
2000 \\
3000 \\
4000 \\
5000 \\
6000 \\
7000 \\
8000 \\
9000\end{array}$ & $\begin{array}{r}0.27 \\
0.57 \\
1.14 \\
1.65 \\
2.10 \\
2.49 \\
2.94 \\
3.36 \\
3.81 \\
4.17 \\
4.50 \\
7.62 \\
10.05 \\
12.39 \\
14.64 \\
16.71 \\
18.60 \\
20.46 \\
22.17\end{array}$ \\
\hline
\end{tabular}

tients into 4 categories: those who may have concentrations within the normal range, and those with a slight, a moderate, or a pronounced elevation of concentration.

There are conditions in which the color of the serum is altered and then we cannot use the direct method. Bilirubinemia is an example, though one rarely seen in ambulatory patients with renal disease. Hemoglobinemia is more common, but it is almost invariably an artifact. ${ }^{1}$ Lipemia constitutes our almost sole source of difficulty. The fat alters the quality of the color and when we try to read it against the dichromate tubes we find that we somewhat overestimate the creatinine concentration. As might have been anticipated, we failed to find any fat solvent, and we have tried many, that is able to clear these lipemic sera. In such cases, or when the serum is colored with bile pigment or hemoglobin, we can get water-clear filtrates by precipitating the color along with the se-

1 We draw the blood into a vaselined syringe. The needle is detached before transferring the blood to a centrifuge tube in which it is allowed to clot. When the blood is forced through the needle, some lysis of red cells may be induced. rum proteins. We take $1.5 \mathrm{ml}$. of serum in a graduated centrifuge tube, add $3 \mathrm{ml}$. of $0.5 \mathrm{M}$. sodium acetate-acetic acid buffer at $\mathrm{pH} 5$ to the $4.5 \mathrm{ml}$. mark, mix, close with a vaccine stopper through which a hypodermic needle is inserted, and place the tube in a beaker of boiling water for 5 minutes. The coagulum is then emptied onto a small filter and, when a litle more than $1 \mathrm{ml}$. of filtrate has run into a graduated centrifuge tube, the filter is removed and the volume reduced to exactly 1 $\mathrm{ml}$. by a capillary pipette. Then we add $0.5 \mathrm{ml}$. of undiluted alkaline picrate $(1 \mathrm{ml}$. of 10 per cent sodium hydrate plus $5 \mathrm{ml}$. of 1.175 per cent picric acid). The interval timer is set to ring at $10 \mathrm{~min}$ utes and the comparison is made with the dichromate standards given in Table I for the filtrate method.

This filtrate method was the one we first developed. It was conjoined with a similar method for the determination of the rate of creatinine excretion in the urine. Desiring a method requiring no more apparatus than graduated centrifuge tubes and capillary pipettes, and avoiding the need for color standards, we diluted the urine color until it matched the color of the serum and thus derived an approximate "creatinine clearance." However, by comparison with results obtained on the same serum and urine by precision methods, and through experiments on rats from which known proportions of the total renal tissue had been removed, we learned that, as a rule, a decrease in creatinine clearance arose not from any diminution in the rate of creatinine excretion but from an increase in the concentration of creatinine in the serum. So when we found that we were able to approximate the serum creatinine concentration without removing the protein and usually learn as much from it as we could from a clearance, we felt that we had probably reached that maximum of rapidity and ease of operation that is an indispensable prerequisite for a clinical as contrasted with a laboratory method.

It seems to us that this distinction between what we call laboratory and clinical methods necessarily involves a differentiation in the criteria by which they should be judged. A laboratory method belongs to science. It is an instrument for an exact description, under isolated and controlled experimental conditions, of what is measured. For this purpose a high order of average precision is ad- 
vantageous. Often this precision requires a considerable complexity of mechanism. Occasionally a fault in one or other of the elements involved may lead to large error. The scientist accepts this possibility with equanimity. He knows that in the end such errors will reveal themselves as gross deviations from the general law he intends to derive from his measurements. A clinical method, on the other hand, is a doctor's tool. Reliability in each and every observation rather than average precision is its virtue. It is best, therefore, if the method has such a transparent simplicity that any error in its operation is at once apparent. The clinician is looking not for that which is general and abstract but for that which is individual and concrete. Every patient is for him an end. So he cannot afford to use a method, no matter how precise, that may at times mislead him with respect to the individual. What he wants is a universal dependability within known limits of error that need not be so very narrow.

We have evaluated this clinical method in terms of its greatest errors. In 93 patients the serum creatinine concentration was estimated by the standard Folin-Wu method, using the Evelyn colorimeter as well as by the direct addition of sodium picrate to serum (the clinical method). The series was divided into 4 groups: first, those in whom the serum creatinine concentration was not certainly abnormal, and the other 3 into those with slight, moderate, and pronounced increases in concentration. In Table II we give the maximum minus and plus errors of the direct clinical method for each group on the assumption that the photoelectric measurement gave us correct values.

In Table II we give the minus errors first because it is they that are dangerous. Even in these worst examples there is no case in which we were seriously misled. Always we were able to pick
TABLE II

The largest errors incurred in the District Clinical Method as derived from comparison with determinations made by the precision method

\begin{tabular}{l|c|c|c}
\hline $\begin{array}{c}\text { Clinical } \\
\text { subdivision }\end{array}$ & $\begin{array}{c}\text { No. of } \\
\text { patients }\end{array}$ & Minus errors & Plus errors \\
\hline $\begin{array}{c}\text { Possibly } \\
\text { normal }\end{array}$ & 63 & 0.6 instead of 1.2 & 2.1 instead of 1.1 \\
$\begin{array}{c}\text { Slight } \\
\text { retention } \\
\begin{array}{c}\text { Moderate } \\
\text { retention }\end{array}\end{array}$ & 9 & 3.0 instead of 3.3 & 3.0 instead of 2.3 \\
$\begin{array}{c}\text { Marked } \\
\text { retention }\end{array}$ & 6 & 7.9 instead of 9.3 & 9.3 instead of 8.1 \\
\hline
\end{tabular}

out the patients who had an increase clinically important to recognize. We believe, therefore, that this is a dependable method in the clinical sense, for in many hundreds of observations made since this series was completed there has been no single patient with serious renal failure that we have failed to detect by this simple procedure.

\section{CONCLUSIONS}

1. A clinical method designed to reveal the existence of varying levels of increase in serum creatinine concentration is described.

2. A modification of the method is given for use when the serum is lipemic or colored with bilirubin or hemoglobin.

\section{BIBLIOGRAPHY}

1. Addis, T., Barrett, E., Poo, L. J., and Yuen, D. W., The relation between the serum urea concentration and the protein consumption of normal individuals. J. Clin. Invest., 1947, 26, 869.

2. Barrett, Evalyn, and Addis, T., The serum creatinine concentration of normal individuals. J. Clin. Invest., 1947, 26, 875 .

3. Folin, O., Beitrag zur Chemie des Kreatinins und Kreatins im Harne. Zeit. f. physiol. Chemie., 1904, 61, 223. 